\title{
Os Usos da Língua Waiwai entre os Povos Indígenas do Mapuera
}

\author{
The Uses of the Waiwai Language among the Indigenous Peoples of Mapuera
}

\author{
Lúcia Maria Silva Rodrigues \\ Universidade Federal do Pará (UFPA) \\ Sidney da Silva Facundes \\ Universidade Federal do Pará (UFPA)
}

Resumo. Este trabalho de pesquisa trata de fenômenos de usos linguísticos entre os povos indígenas falantes da língua Waiwai da família Karib, nos limites do Extremo Norte (Nordeste da Cidade de Manaus-Brasil), nos Estados do Pará e Amazonas, especificamente nas Terras Indígenas do chamado Complexo Cultural Tarumã Parukoto (em homenagem aos antigos povos indígenas Tarumã e Parukoto que habitavam as áreas das então Terras Indígenas), hoje demarcadas pelo Governo Federal, todas banhadas pelas bacias dos Rios Nhamundá, Mapuera, Cachorro e Alto Trombetas. Os dados coletados por Rodrigues (2012) contribuem de forma importante para os novos estudos sobre os usos das línguas indígenas faladas pelos povos Karib e outras etnias entre as diversidades sociolinguísticas existentes dos povos da região Amazônica. Busca-se observar na presente proposta, os usos da língua Waiwai falada pelos os povos indígenas presentes no Complexo, quando a usam e qual motivação de uso em seus discursos no seu dia a dia. Com base em dados coletados nas pesquisas, propõe-se uma análise sobre qual a importância de uso da língua Waiwai como língua mais fala pelas etinias consultadas; de qual a motivação de uso da língua Waiwai entre as etnias; da importância dos movimentos de fusão e dispersão entre as etnias como influência para o uso da língua Waiwai; o ensino da língua Waiwai como língua de nascimento como construção de sua história e a continuação dela entre os diferentes povos indígenas com o passar dos anos, em constante luta de resistência.

Palavras-chave: Família Karib. Língua Waiwai. Bi/-Multilinguismo. Educação Indígena. Complexo Cultural Tarumã Parukoto.

Abstract. This research work deals with phenomena of linguistic uses among indigenous speaking peoples of the Waiwai language of the Karib family, on the edge of the Far North (Northeast of the City of ManausBrazil), in the States of Pará and Amazonas, specifically in the Indigenous Lands of the so-called Cultural Complex Tarumã Parukoto (in honor of the ancient Tarumã and Parukoto indigenous peoples who inhabited the areas of the then Indigenous Lands), now demarcated by the Federal Government, all are bathed by the basins of the Rivers Nhamundá, Mapuera, Cachorro and Alto Trombetas. The data collected by Rodrigues (2012) contribute to important form for new studies on the uses of indigenous languages spoken by the Karib peoples and other ethnic groups among the existing sociolinguistic diversities of the peoples of the Amazon region. We seek to observe in this proposal, the uses of the Waiwai language spoken by the indigenous peoples present in the Complex, when they use it and what motivation to use in their speech in their daily lives. Based on collected data in the research, an analysis is proposed about the importance of using the Waiwai language as that most spoken for the ethnic groups consulted; what is the motivation for using the Waiwai language among ethnic groups; the importance the movements of fusion and dispersion among ethnicities as an influence for the use of the Waiwai language; the education of the Waiwai language as the birth language in the construction of its history and its continuation among the different indigenous peoples over the years, in constant struggle for resistance.

Palavras-chave: Karib Family. Waiwai Language. Bi/-Multilingualism. Indigenous Education. Cultural Complex Tarumã Parukoto. 


\section{Introdução}

O objetivo deste artigo é refletir sobre os processos de utilização da língua Waiwai" ${ }^{1}$ "da família linguística caribe (ou Karíb), uma das três maiores e mais espalhadas da América do Sul, junto com as famílias Tupi e Arawak"(MEIRA, 2006) e seus contextos socioculturais em meio às muitas línguas indígenas existentes na região Amazônica, particularmente as pertencentes aos povos que foram no passado denominados por Protásio Frikel (1958), conforme citado por Caixeta de Queiroz (2014, p. 168) como povos indígenas do Complexo Cultural Tarumã Parukoto (CCTP). Usaremos essa expressão para poder agrupar, de forma mais específica, em uma só denominação, todas as etnias existentes nas Terras Indígenas Trombetas Mapuera, Nhamundá Mapuera, Waiwai, Waimiri Atroari e a mais nova terra indígena demarcada pelo Governo Federal, Kaxuyana Tunayana, as quais fazem parte desta proposta de estudos.

As pesquisas iniciadas por Rodrigues (2012) e publicados em dissertação de mestrado intitulada. "Educação bilíngue em território indígena waiwai/aldeia Tawanã" contribuem de forma significativa para continuar e ampliar a visão sobre o bi/-multilinguismo e a diversidade sociolinguística dos povos indígenas do Extremo Norte da Amazônia. Nessa nova proposta em estudos de doutorado, buscase investigar e documentar as situações sociolinguísticas de uso das muitas línguas indígenas faladas por diferentes etnias, e particularmente o uso da língua Waiwai, o contato entre os diferentes povos, os fenômenos de bi/-multilinguismo², agora ampliados para novas aldeias indígenas do CCTP que são: Tawanã, Yawará, Passará, Mapium, Kwanamari, Takará, Inajá, Paraíso, Placa, Mapuera, Tamyuru, Pomkuru, Bateria, Hayaramã, Turuni, Kaspakuru, Araça, Santidade, Chapéu e Mahrawani.

Os dados desses estudos foram coletados através de questionários sociolinguísticos com perguntas abertas, semi-estruturadas entre as populações indígenas do CCTP. As informações de ordem qualitativa foram obtidas por meio das observações in loco nas interações sociais no cotidiano das aldeias, de conversas com os indígenas durante a pesquisa de campo, e de follow up questions feitas após análise sociolinguística com os questionários. Já os dados quantitativos foram obtidos apenas por meio dos questionários. Referidos questionários sociolinguísticos foram aplicados contemplando 70 pessoas, sendo estas 38 do sexo masculino e 32 do sexo feminine; 12 pessoas na faixa etária de 15 a 30 anos de idade, 32 pessoas na faixa etária de 31 a 50 anos; 26 pessoas na faixa etária de 51 a 70 anos e10 pessoas com mais de 70 anos (Tabela 1 ).

Realizamos visitas em 9 aldeias indígenas totalizando 2 viagens que, em média, duraram 20 dias cada uma. As consultas feitas, em nossas visitas às aldeias, alcançaram as pessoas nas faixas etárias citadas

1. Para a nomenclatura dos povos indígenas e sobrenomes, foi adotado neste texto o padrão do Quadro Geral do Povos do Instituto Socioambiental (ISA). "Waiwai" quando se trata de povos ou aldeias (como "Brasil): os waiwai quando se referem à população em geral (como "os brasileiros") "Waiwai" quando diz respeito a sobrenome (ISA, 2006).

2. Cenoz (2000 p. 39-53), "a aquisição multilíngue é considerada como a aquisição de outras línguas que não a L1 e a primeira língua estrangeira (L2) do indivíduo". "O multilinguismo configura um processo mais complexo do que a aquisição de uma segunda língua, uma vez que, além de implicar todos os fatores e processos associados à aquisição de $L 2$, o multilinguismo apresenta fatores unicamente e potencialmente mais complexos, além de efeitos associados às interações que podem ocorrer entre as múltiplas línguas que são aprendidas e usadas ao mesmo tempo (BLANK, ZIMMER, 2011.p. 28-40). O conceito de bi/multilinguismo que se coaduna com visões mais atuais pressupõe a existência de um continuum que vai do monolinguismo ao multilinguismo, ou seja, passando por diferentes estados intermediários de processamento e ativação das línguas, ao invés de um estágio exato a partir do qual um sujeito se torna bilíngue (GROSJEAN, 2008) 
anteriormente e tiveram o intuito de observar os usos das variadas línguas indígenas e as suas relações aos seus meios de vida, em seus ambientes de produtividade, de oração nas igrejas, de coleta, de caça e pesca, nas escolas das aldeias, em momentos de lazer ou de preparo de alimentos, da farinha, do preparo das bebidas tradicionais, entre outros. As tabelas 1-2 apresentam os números dos dados dos entrevistados por aldeia e por etnia.

Tabela 1: Aldeias e número de entrevistado(a)s

\begin{tabular}{|c|c|}
\hline NOME DA ALDEIA & ENTREVISTADO(AS) \\
\hline Aldeia Mapuera & 33 \\
\hline Aldeia Inajá & 6 \\
\hline Aldeia Takará & 6 \\
\hline Aldeia Kwanamary & 6 \\
\hline Aldeia Tamiurú & 3 \\
\hline Aldeia Tawanã & 11 \\
\hline Aldeia Paraiso & 15 \\
\hline Total & 70 \\
\hline
\end{tabular}

Tabela 2: Etnias e número de entrevistados

\begin{tabular}{|c|c|}
\hline NOME DA ETNIA & ENTREVISTADO(AS) \\
\hline Katwena & 9 \\
\hline Tiriyó & 3 \\
\hline Hixkaryana & 10 \\
\hline Mawayana & 26 \\
\hline Waiwai & 11 \\
\hline Xereu & 2 \\
\hline Tunayana & 2 \\
\hline Tikiyana & 1 \\
\hline Pakukoto & 70 \\
\hline Total & \\
\hline
\end{tabular}

"A família caribe tem cerca de quarenta membros, repartidos entre vários países da região Amazônica: além do Brasil, há línguas desta família na Colômbia, na Venezuela, na Guiana, no Suriname e na Guiana Francesa" (MEIRA, 2006). Um recorte na pesquisa foi necessário devido à grandiosidade da área selecionada e da variedade de línguas existentes na região. Partimos assim, através das descrições sociolinguísticas das informações coletadas por meio de questionários sociolinguísticos de forma a organizar os dados e entender as manifestações bi/-multilíngues dentre os povos indígenas supracitados, num contexto de grande variedade étnica, assim como a complexidade linguística, tornando-o um laboratório ideal para as pesquisas sobre bi/-multilinguismo entre os povos. Dessa forma, a decisão em se trabalhar na pesquisa com os povos de apenas três áreas indígenas, entre as cinco áreas do CCTP, ocorre porque nos permitirá um foco adequado aos dados encontrados, assim como a sintetização da análise sociolinguística dos usos das línguas faladas pelos povos do CCTP. 
Para tanto, temos como objetivo, observar os resultados dos dados sociolinguisticos e entender qual situação ou qual motivação existe entre os povos nativos para manterem o uso da língua Waiwai, entre as muitas outras línguas indígenas faladas pelas diferentes etnias; observar também, o porquê de se auto denominarem Waiwai, falantes da língua Waiwai, já que essa é apenas uma das muitas outras línguas existentes na região; destacar o bi/-multilinguismo e quais os fatores sociolinguísticos que favorecem esses fenômenos de uso de uma ou outra língua indígena; compreender as necessidades políticas, religiosas ou culturais no uso da língua Waiwai; quais as relações de interdependência em suas trajetórias nos movimentos de dispersão e de fusão entre os grupos indígenas do Território Wayamu. Para ancorar estas pesquisas sociolinguísticas, buscamos conceitos teóricos embasados nos estudos sociolinguísticos e socioculturais de pesquisadores renomados como: Aracil (1965), Baker (1993), Bakhtin (1992), Calvet (2009), Cummins(1981), Ferguson (1959), Fishman (1999), Frikel (1958), Guppy (1958), Hawkins (1952), Howard (2002), Meira (2006), Porro (2008), Queiroz (2004), Romaine (1994), Viveiros de Castro (2002), Zea (2006), entre outros.

A seguir faremos um breve esclarecimento a respeito das terras e das etnias tratadas neste estudo.

\section{Complexo Cultural Tarumã Parukoto: Território Wayamu}

Esta denominação foi criada em homenagem aos descendentes dos primeiros povos Tarumã e Parukoto, que no passado viviam nessa região do Brasil. Atualmente, são cinco grandes áreas indígenas oficialmente demarcadas pelo Governo Federal: Terra Indígena Nhamundá Mapuera (AM/ PA), Trombetas Mapuera (AM/RR/PA), Wai-Wai (RR), Waimiri Atroari (AM/RR) e Kaxuyana Tunayana (AM/PA), como devidamente demonstradas na Figura 1.

Figura 1: Complexo Cultural Tarumã Parukoto

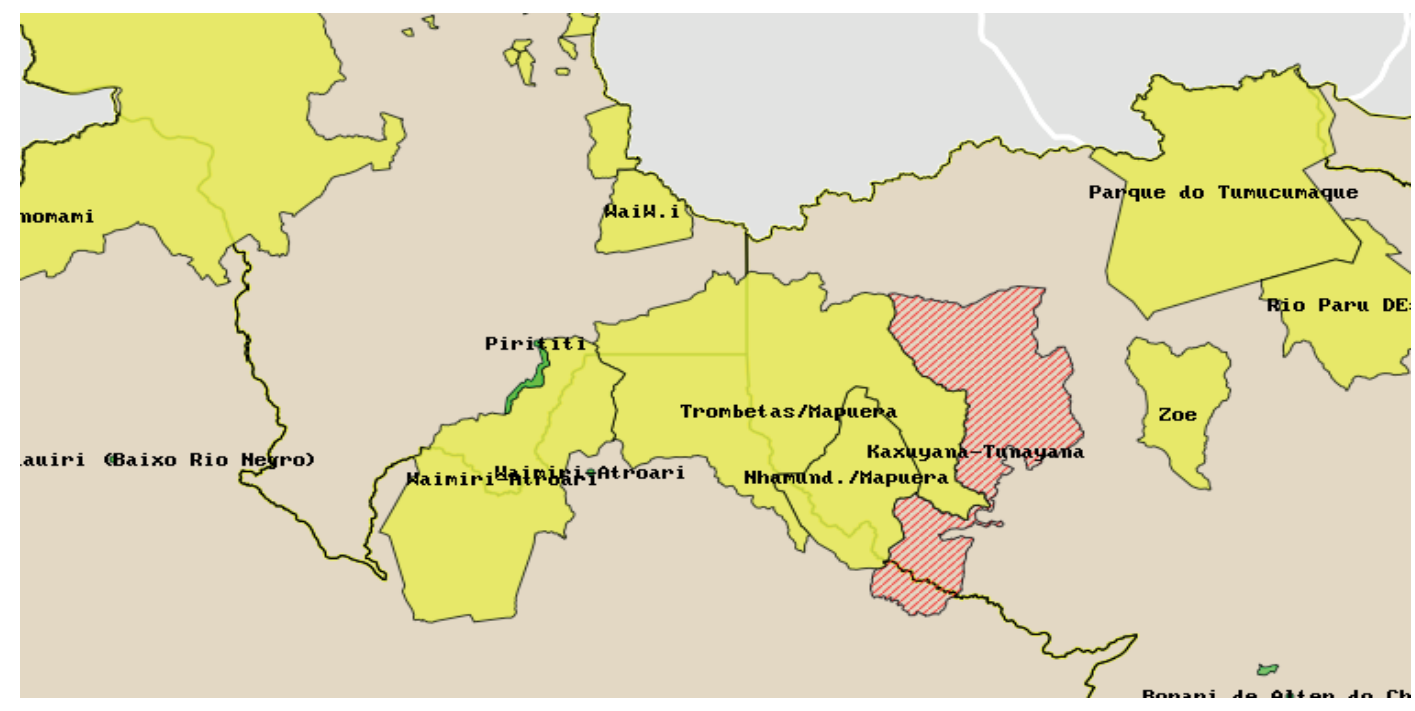

Fonte: FUNAI 2020

Este trabalho de pesquisa foi delimitado e executado entre os povos indígenas de apenas três terras demarcadas e integrantes do CCTP a saber:Terras Indígenas Trombetas Mapuera, Nhamundá Mapuera e Kaxuyana Tunayana às quais tivemos acesso e desenvolvemos nossas pesquisas. Essas três terras 
indígenas foram denominadas em 2019 pelos povos indígenas que lá residem, como Território Wayamu ou jabuti-réptil que consegue sobreviver durante meses no interior da mata, sem comida e sem água - um bicho obstinado e resistente (CAIXETA DE QUEIROS, 2020).

Há muitas décadas, os povos indígenas que ocuparam as bacias dos rios da região do CCTP, assim como a maioria dos povos indígenas da Amazônia, vêm enfrentando ameaças constantes às suas línguas e, consequentemente, à sua cultura. Missionários evangélicos começaram os movimentos de "unificação" dos povos do CCTP no passado, usavam essas estratégias como controle social ("pacificação") na tentativa de inseri-los "na palavra" ou seja, ao Evangelho Cristão. A história remonta aos tempos em que vivia o lendário xamã Ewka Wai Wai, líder que foi parte importante nos planos de evangelização dos povos da região.

As ameaças atuais, evidenciam e se materializam na imposição da língua nacional (a língua portuguesa), que é ensinada nas escolas das aldeias, em grande maioria por professores não indígenas. Assim como ameaças de influências externas às aldeias envolvem o uso das novas tecnologias digitais pelos jovens, novamente com a utilização da língua nacional como língua de comunicação, o que introduz diferentes usos linguísticos distintos daqueles de suas línguas de nascimento3, entre as diferentes gerações, seguindo em direção contrária à traçada pelos mais experientes, referentes ao seu patrimônio linguístico e cultural provindos de suas origens.

Para sabermos um pouco mais sobre o povo Waiwai, seu contexto cosmológico, e o seu status no contexto sociocultural, é necessário atentarmos para as mudanças internas e externas que estes vêm sofrendo no decorrer de algumas décadas em suas comunidades indígenas. Em 1958, o missionário e antropólogo Günther Protásio Frikel, escolheu denominar os povos que viviam espalhados nas comunidades indígenas como "Complexo Cultural Tarumã Parukoto". Na época dessa denominação, apontava-se a existência de quinze etnias: Waiwai, Xereu, Katuena, Kamarayana, Pianokoto, Parukwoto, Hixkaryana, Mawayana, Tikyana, Xowyana, Cikiana, Tunayana, Kaxuyana, Karapawyana e Yaipîyana, além de grupos indígenas isolados, segundo Frikel (1970).

Entretanto, em 2012 durante as visitas as aldeias indígenas para coleta de dados, em conversas informais com diferentes os amigos waiwai, atestamos a presença de dezesseis etnias a saber:Waiwai, Xereu, Katuena, Parukoto, Hixkaryana, Mawayana, Tikyana, Xowyana, Kaxuyana, Karapawyana, Tiriyó, Wapixana, Tunayana, Kahyana, Xereu-Hixkaryana, Xereu-Katuena, além dos povos indígenas isolados.

Como demonstraremos a seguir, o Waiwai é a língua mais falada no CCTP de acordo com os dados sociolinguísticos. Começamos a compreender essa predominância de Waiwai quando observamos as líderanças, os caciques, os missionários religiosos, os caçadores, os coletores, os professores indígenas, os agentes de saúde indígenas, entre outros, agem como agentes difusores nos processos de fortificação da língua Waiwai entre as etnias nas aldeias, uma vez que elaboram seus discursos em língua Waiwai mantendo seu status de língua majoritária entre as outras línguas indígenas. Para tanto observamos, também os recentes processos de valorização entnocultural feitos da língua Waiwai na forma da elaboração de um vocabulário impresso, da produção de bíblias traduzidas do inglês para a

3. O termo "língua de nascimento" é adotado (informalmente) neste trabalho para denominar a primeira língua que a criança aprende em casa, independentemente se ela se tornará L1 ou L2 dessa criança, ou se é a L1 do pai, da mãe ou de outra pessoa. 
língua Waiwai, do uso de waiwai nas igrejas e nos estudos bíblicos, assim como nos cânticos ensaiados nos cultos, entre outros fatores que, combinados contribuem para a fortificação da língua Waiwai em detrimento de outras línguas indígenas faladas entre os povos do CCTP.

Entre várias comunidades indígenas, falantes ainda de suas línguas de nascimento, que ainda sobrevivem na região entre os vários povos indígenas que formam o CCTP, as etnias que fazem parte da família Karib são: Waiwai, Katwena, Kaxuyana, Tiriyó, Hixkaryana, Tunayana, Xereu, Tikyana. Esses povos indígenas encontram-se distribuídos em vinte aldeias a saber: Tawanã, Yawará, Passará, Mapium, Kwanamari, Takará, Inajá, Paraíso, Placa, Mapuera, Tamyuru, Pomkuru, Hayaramã, Turuni, Kaspakuru, Araça, Santidade, Chapéu, Mahrawani e Bateria. Entre todas essas etnias citadas é possível identificar durante a coleta de dados dez línguas indígenas em uso a presentadas pelos falantes nas aldeias que são: Waiwai, Hixkaryana, Xereu, Tiriyó, Kaxuyana, Katwena, Mawayana, Wapixana, Tikyana e Tunayana.

A miscigenação entre os povos indígenas do Complexo no contexto de diferentes línguas em uso contribui para a manutenção desses usos linguísticos e das misturas que ocorrem entre eles, o que pode ser observados e analisado para que se possa entender como tantas línguas convivem e sobrevivem entre esses povos do Complexo. Essas variedades linguisticas espalhadas em diferentes aldeias ocorrem por diferentes fatores como por exemplo: casamentos interétnicos, em que os homens viajam em missões religiosas (congressos, conferências, caravanas) quando acabam por conhecer uma companheira para formar uma nova família, a qual deve estar, de preferência, em uma aldeia distante, que seja de diferente etnia de seu companheiro, para que não haja consanguinidade na união do novo casal; movimentos de fusão e dispersão entre etnias, para a formação de novas aldeias ou extinção delas; deslocamentos por motivos alimentícios (plantio em solo fértil), ou por busca de solos sagrados (sempre buscam construir uma nova aldeia no solo que já pertenceu a seus ancestrais); no comércio com as cidades distantes do Complexo; influência de línguas não indígenas como a língua portuguesa e a língua inglesa de seus pares vindos da Guiana Inglesa, do Suriname ou missionários americanos vindos dos Estados Unidos.

Observando fatores importantes, como por exemplo, os que expõem a diversidade sociolinguística existente entre esses povos do Complexo, é relevante que se possa entender a dinâmica das etnias em contato no seu dia a dia, para em seguida compreender como todas essas características contribuem para a formação sociolinguística, tornando os povos do Complexo, povos indígenas singulares entre os outros povos indígenas do Brasil.

\section{LÍngua Waiwai / Língua De Nascimento}

Entre os processos linguísticos de substituição, devemos notar que grupos minoritários não são totalmente homogêneos, mas compreendem diferentes subgrupos e atitudes frente à utilização de uma língua de nascimento. Portanto, indivíduos ou grupos de indivíduos podem promover a utilização da língua minoritária dentro do contexto familiar. Consideramos que a família seja o domínio mais importante para a manutenção das línguas minoritárias de nascimento, pois percebemos que é nela que, na maioria das vezes, a referência do sujeito é construída.

Dessa forma, é clara a importância em se falar unicamente a língua de nascimento, de maneira sistemática e consequente, ao se dirigir aos filhos dentro do ambiente doméstico, como forma de incentivar a manutenção de sua língua de nascimento. Romaine (1995) sugere formas variadas de aquisição de línguas que caracterizarão a criança como um ser bilíngue. Assim, quando temos pais com 
línguas nativas diferentes, a estratégia utilizada é a de cada um falar a sua própria língua com a criança, deixando-a exposta à língua dominante quando encontrar-se em um ambiente externo.

A entrada da escola nas aldeias com padrões de ensino pautados na língua majoritária (língua portuguesa), bem como a falta de material didático em língua de nascimento é um ponto desfavorável para a manutenção da língua de nascimento. Ainda que a língua de nascimento seja usada nos demais ambientes socioculturiais, é provável que a língua usada na escola adquira um status de prestígio que possa influenciar negativamente o interesse de gerações futuras pela língua de nascimento, se esta é deixada de fora do domínio escolar e de outros domínios que envolvam o uso de tecnologias alheias às tradições socioculturais associadas ao uso da língua de nascimento. Entretanto, nossos dados sugerem que o uso de suas línguas de nascimento diariamente em ambiente familiar, nas igrejas, na caça, na pesca, na lavoura, em viagens no barco indígena subindo ou descendo o Rio Trombetas, em momentos de lazer ou em comunicações pelo rádio garante a manutenção e a sobrevivência da língua indígena de nascimento naqueles domínios de uso.

Devemos mencionar também que, em período escolar, as crianças necessitam frequentar a escola, estudarem L2 (língua portuguesa), orientada e aplicada pela sociedade não indígena, usando conteúdos, em língua portuguesa os quais ainda não estão adequados ao ritmo, a cultura ou as necessidades dos alunos indígenas. Segundo Leiria, (2004),"o termo LS (língua segunda) deve ser aplicado para classificar a aprendizagem e o uso de uma língua não-nativa dentro de fronteiras territoriais em que ela tem uma função reconhecida". Há nesse ponto um grande esforço pelas crianças indígenas no sentido a compreender o educador que usa uma língua distinta da sua língua de nascimento e escreve conteúdos que lhe parecem completamente estranhos e fora de seu contexto diário na aldeia.

Dessa maneira, percebemos no ambiente da escola o enfrentamento de uma língua diferente de suas línguas de nascimento, impedindo o uso destas no domínio de uso escolar, ameaçando a vitalidade futura das línguas indígenas maternas, principalmente para aquelas de minorias étnicas formadas por grupos díspares que vêm de outras regiões, como por exemplo os povos indígenas que vêm da Guiana Inglesa (usando a língua Inglesa ou a língua Waiwai), bem como outros vindos da Serra do Tumucumaque, os Tiriyó (usando a língua Tiriryó) ou povos indígenas de outras etnias

Observando as tradições presentes nos hábitos cotidianos dos diversos grupos indígenas que fazem parte do CCTP, representantes das TIs Trombetas Mapuera, Nhamundá Mapuera e Kaxuyana Tunayana é que se fez possível acompanhar as formas de uso e de manutenção da língua de nascimento apresentadas pelos povos indígenas em suas produções diárias e como se esforçam para resistir e conservar seu patrimônio linguístico.

Dentre as muitas atividades elaboradas em suas rotinas diárias, é comum observarmos como se dão as trocas culturais e linguísticas entre os integrantes da mesma família ou entre integrantes de famílias diferentes. Essa interação entre os indivíduos serve como forma de perpetuação da cultura indígena e divulgação dos ensinamentos em suas línguas tradicionais dos referentes povos do CCTP, passados de geração a geração através da suas línguas. Esse elo linguístico serve como uma combinação subjetiva de usos comunicacionais e práticas discursivas e práticas sociais produtivas das comunidades, ligando as pessoas da mesma ou de diferentes etnias.

Um dos exemplos bem claros, sobre a manutenção da língua de nascimento através das práticas produtivas que observamos muito in loco e que podemos descrever aqui é a prática da agricultura 
entre as famílias. Observamos que, geralmente, os roçados são distribuídos e preparados em espaços separados e um pouco distantes das aldeias, são feitos por uma mesma família a qual trabalha unida todos os dias para o andamento do roçado. Os genros fazem o trabalho mais difícil que é a preparação da área a ser plantada com a derrubada da mata, a queimada das árvores para liberação do terreno. Em seguida todo o serviço fica a cargo das mulheres e dos adolescentes. Nesse momento de interação e cooperatividade é que as trocas linguísticas acontecem. Os membros da mesma família ou de outras famílias passarão muitos dias preparando o roçado (práticas de coivara) para o plantio da mandioca, macaxeira, cana, algodão, abacaxi, cará, batata, banana, entre outros. Toda essa produção é feita pelas mulheres mais velhas que ensinam a técnica de plantio para os menores, na língua de nascimento. Cantam músicas do passado, na língua de nascimento, ensinam as lendas e os feitos históricos para os mais jovens.

Diante dessas experiências de observação das práticas de trocas linguísticas dos mais idosos para os mais jovens, podemos constatar como um povo ágrafo mantém seus costumes e crenças por séculos através da comunicação oral. Em todos os momentos das fases de produtividade, os povos indígenas vão vinculando de forma oral, sua língua de nascimento, às culturas recebidas no passado por seus ancestrais para os mais novos. Assim também acontece com as práticas de caça, pesca e de coleta, dessa vez feitas pelos homens mais velhos das comunidades. Estes, tomam a atenção dos mais jovens, contando seus feitos e seus ensinamentos os quais receberam de seus pais no passado que também receberam de seus respectivos pais. Há de se ressaltar que esses ensinamentos de técnicas produtivas são feitos em língua de nascimento.

\section{Análise dos Dados}

Estes estudos foram realizados em 7 comunidades indígenas entre as 20 comunidades que fazem parte do CCTP: são elas, Mapuera, Inajá, Takará, Kwanamary, Tamiuru, Tawanã e Paraiso. Eles foram realizados através de exames qualitativos e parcialmente quantitativos (ainda sem tratamento com vistas a determinar significâncias estatísticas), de forma à identificar os fenômenos sociolinguísticos pertinentes ao uso de waiwai, em seu contexto social. Buscamos nesses dados correlações entre os domínios socioculturais e suas funções no uso da língua Waiwai como fatores sociolinguísticos.

A convivência entre todas essas variedades étnicas, constatadas e observadas em visitas às aldeias dos povos indígenas do CCTP, nos ajudam a entender um pouco mais sobre as peculiaridades socioculturais e sociolinguísticas das citadas etnias, assim como sobre o status que as línguas faladas naquela região ocupam. Para isso devemos ressaltar as forças culturais antagônicas que operam nesses processos sociolinguísticos, uma no sentido de manter a diversidade etnocultural dos povos indígenas como a ancestralidade e tudo aquilo que vem atrelado às memória de seus antepassados e sua identidade étnica, outra no sentido de homogeneização sociolinguística tornando a língua Waiwai a língua majoritária, por questões sociopolíticas, ou na tentativa de tornar a língua Waiwai a língua de prestígio, a língua mais forte em uso entre os diferentes povos indígenas no agrupamento de línguas no CCTP. Na Figura 2, mostramos a distribuição percentual das etnias identificadas e relacionadas com as línguas indígenas faladas pelos povos do CCTP, em que a etnia waiwai representa $37 \%$ do total das etnias consultadas: 
Figura 2: Etnias existentes no CCTP e sua distribuição proporcional nos dados da pesquisa

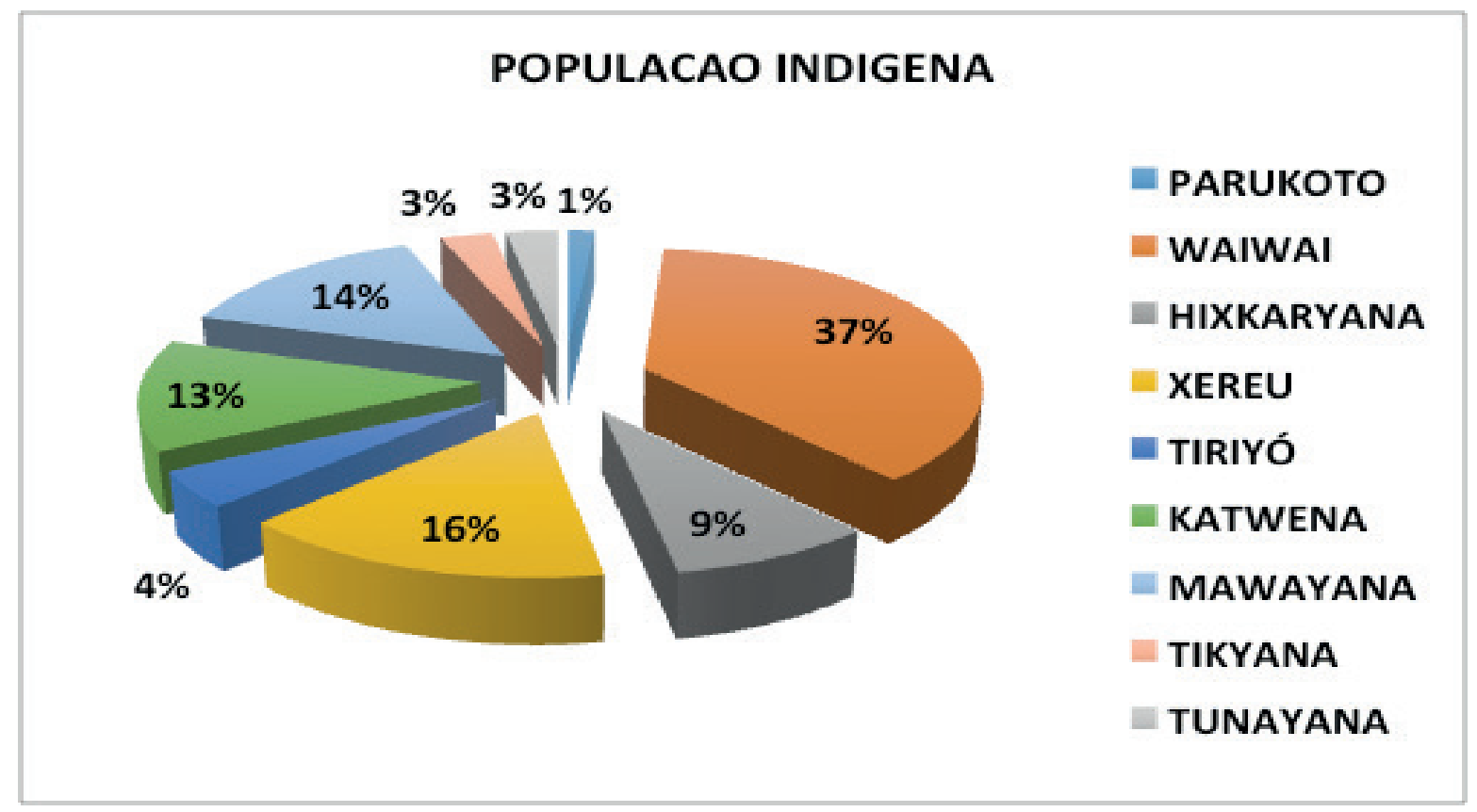

Fonte: RODRIGUES (2020)

Foi possível observar as práticas discursivas e a supremacia da lingua Waiwai entre as outras línguas indígenas usadas no CCTP, a partir de alguns comportamentos sociais de interação entre os grupos indígenas, como por exemplo, quando estão em momentos de caça, da pesca, de coleta, na igreja, nas atividades produtivas, na escola, nas viagens e nos jogos esportivos. . Os discursos ocorrem ora na língua de prestígio, a língua waiwai (quando em interação de modo geral com outros indígenas), ora em sua língua de nascimento (quando em interação no âmbito familiar ou de parentesco em etnia de nascimento). Essa condição sociolinguística é bem resolvida entre eles, de forma a reforçar os processos de multilinguismo apresentado entre os diferentes grupos étnicos.

Entre esses múltiplos traços sociolinguísticos, étnicos e culturais existentes no CCTP, observamos que é através das políticas internas apresentadas em cada aldeia, as quais identificam-se e usam sua linguagem, sem deixar de participar das políticas de fortalecimento da língua Waiwai, para que, dessa forma, não percam os benefícios tangíveis em seu grupo. Atuam coletivamente, exercendo e, ao mesmo tempo, sofrendo influência direta como membros do CCTP, em comunidades coesas e unificadas em se tratando das questões de usos linguísticos. Observa-se que os povos indígenas, em seus ambientes naturais, não só constroem os sistemas linguísticos, como também o sistema simbólico representacional e referencial para seus parentes, que os permite interpretar as expressões das línguas naturais, estabelecendo relação com o mundo e com eles mesmos. De forma que buscam através das atividades linguísticas atuar efetivamente sobre sua realidade. Ou seja:

A linguagem não é o espelho do 'mundo' em uma semântica inocente. Nem 'constitui' a realidade. A linguagem é determinada, por um lado, pelos modos de operar simbolicamente sobre o 'mundo' e, por outro lado, pelos modos de operar concretamente sobre o 'mundo': representações e experiências concretas se 'estruturam', pois, dialeticamente (FRANCHI, 2002). 
Questões internas referentes a sociolinguísticas entre os povos do CCTP, ocorrem frequentemente influenciando com eficácia positiva os comportamentos das comunidades indígenas que estão presentes e que fazem do CCTP um ambiente singular perante as outras realidades dos outros povos indígenas presentes no Brasil. No contexto do CCTP, estas características são avaliadas pelos seus membros como pontos positivos de um ponto de vista sociopolítico, haja vista, que essa diversidade e a recente conscientização linguística adotada por eles, voltada para a sensibilização à diversidade linguística e cultural tem sido uma das estratégias mais importantes para promover o multilinguismo e consequentemente, a manutenção de línguas indígenas minoritárias de nascimento em uso naquela região.

Sabemos que não há manutenção, revitalização/vitalização ou promoção de uma língua sem que exista a consciência por parte do falante do valor dessa língua e da importância dessa ação, assim, a principal forma de articular a conscientização linguística é através do conhecimento. Segundo Hawkins (1984) e Broch (2014), a sensibilização à diversidade linguística e cultural, entre outras coisas, favorece as representações e atitudes frente às línguas em contato e o desenvolvimento de uma cultura linguística multiétnica. Por meio dessa prática, os povos indígenas modificam suas atitudes em relação às línguas e aos grupos que as utilizam, mostrando-se mais interessados pelas línguas e pela cultura de seu povo, obtendo melhores resultados na preservação de seu patrimônio multilíngue e multicultural. Confirmando-se nossas impressões iniciais sobre as comunidades estudadas neste trabalho, um exame mais atento das estratégias sociopolíticas e linguísticas adotadas na região do CCPT nos parece necessário como veremos a seguir.

Como mostra a Figura 3, 76\% ( 53 do total de 70 entrevistados) dos entrevistados identificaram waiwai como língua de nascimento ${ }^{4}$. Esses dados nos forçam a fazer um ajuste na nossa hipótese de pesquisa apresentada na seção anterior, e que propunha uma forte associação entre ser waiwai e falar waiwai. Enquanto 53 (do total de 70) entrevistados declararam ser waiwai sua língua de nascimento, apenas 26 entrevistados se identificaram como membros da etnia waiwai. Com isso, concluímos que a forte associação é entre ser Waiwai e falar waiwai, não tanto em falar waiwai e ser waiwai.

Figura 3: Línguas de nascimento entre os povos indígenas do CCTP

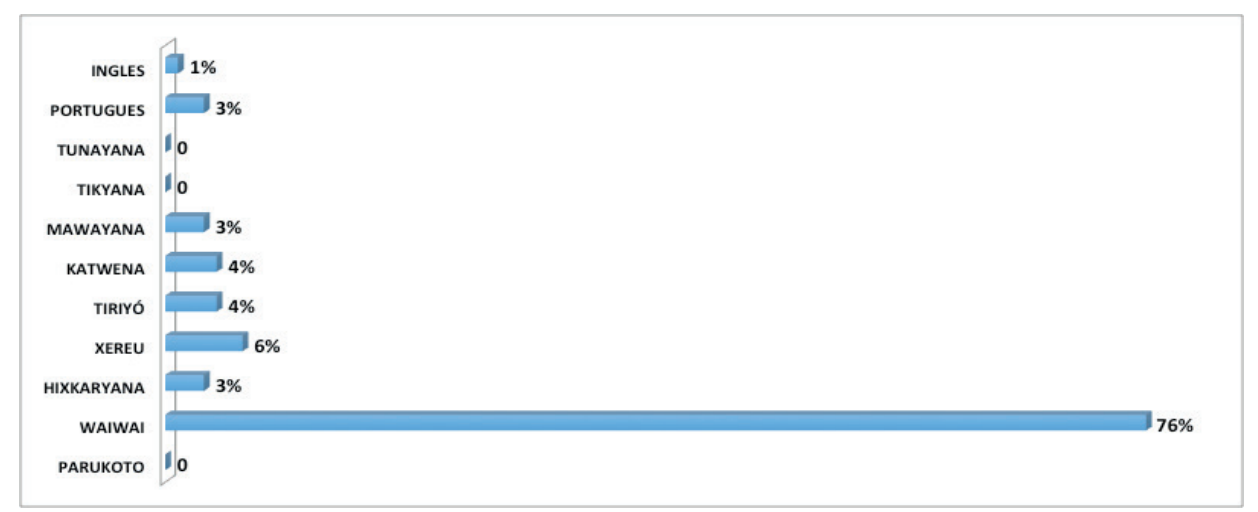

Fonte: RODRIGUES (2020)

4. Na resposta ao questionário, os entrevistados informaram a língua que consideravam ser sua língua materna, o que, no caso, é não apenas a língua de nascimento, mas também aquela associada à sua mãe. 
Diante da variedade étnica, linguística e cultural dos povos do CCTP, o fato que nos chama a atenção é que, apesar desses povos indígenas, apresentarem características culturais e linguísticas diferentes, , eles tendem a escolher, talvez por opções políticas ou religiosas, se auto determinar povo waiwai. Isso geralmente ocorre por entenderem que, dessa forma, estão mais bem representados etnicamente. Assim, mesmo que nascidos de diferentes etnias, assumem a etnia waiwai e aprendem a língua Waiwai de forma a se auto identificarem falantes da língua Waiwai como L1. Como mostra a figura 4, além de assumirema língua Waiwai como L1 a grande maioria dos entrevistados acaba também assumindo a etnia waiwai.

Figura 4: Etnias observadas no CCTP

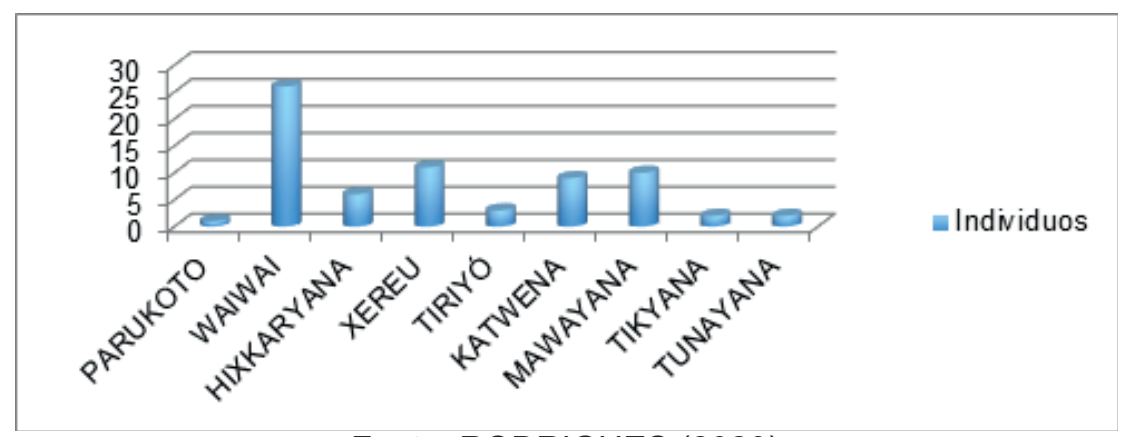

Fonte: RODRIGUES (2020)

A relação entre língua e etnia com os Waiwai reforça-se historicamente mesmo em situações em que os homens viajam para aldeias distantes em busca de uma esposa de etnia diferente da sua, para que, dessa forma, evitem o casamento consanguíneo. Ao encontrar uma esposa para formar uma nova família, mesmo que essa companheira não seja Waiwai, geralmente, os filhos descendentes do novo casal, assumirão a etnia waiwai e a língua Waiwai como língua de nascimento, mesmo quando são criados em outra aldeia, o mesmo se aplica quando a mãe é Waiwai e o pai é de outra etnia. Assim, primam por tornar-se mais fortes politicamente de forma aocupar espaços socioculturais de um povo mais unificado. Valendo-se desses fenômenos sociolinguisticos, buscam representatividade para lutarem por seus direitos, haja vista que, dessa forma, tornam-se mais numerosos em busca de seus direitos. Essa atitude sociopolítica contribui deveras para o crescimento da etnia e da língua Waiwai, a qual está se consolidado como majoritária entre as outras etnias e línguas faladas naquela região, consequentemente fazendo com que as outras etnias e suas línguas se tornem minoritárias.

Na Figura 5, observamos que 99\% (25 de um total de 26) dos entrevistados se declaram pertencentes à etnia waiwai também se declaram falantes de waiwai, um percentual só inferior aos falantes de Tikyana, que, no entanto, constituem um população muito pequena, se comparada à população dos Waiwai. A única entrevistada da etnia waiwai que não fala wawai é, sintomaticamente, a única entre os entrevistados dessa etnia que vive na cidade e não na aldeia. Esta correlação entre língua e etnia indica uma associação muito forte entre as duas, reforçando nossa hipótese de que o predomínio da língua Waiwai está relacionado com o papel dessa língua na simbologia da identidade sociocultural e política da etnia waiwai. 
Figura 5. Multilinguismo- Línguas faladas no Complexo Cultural Tarumâ Parukoto

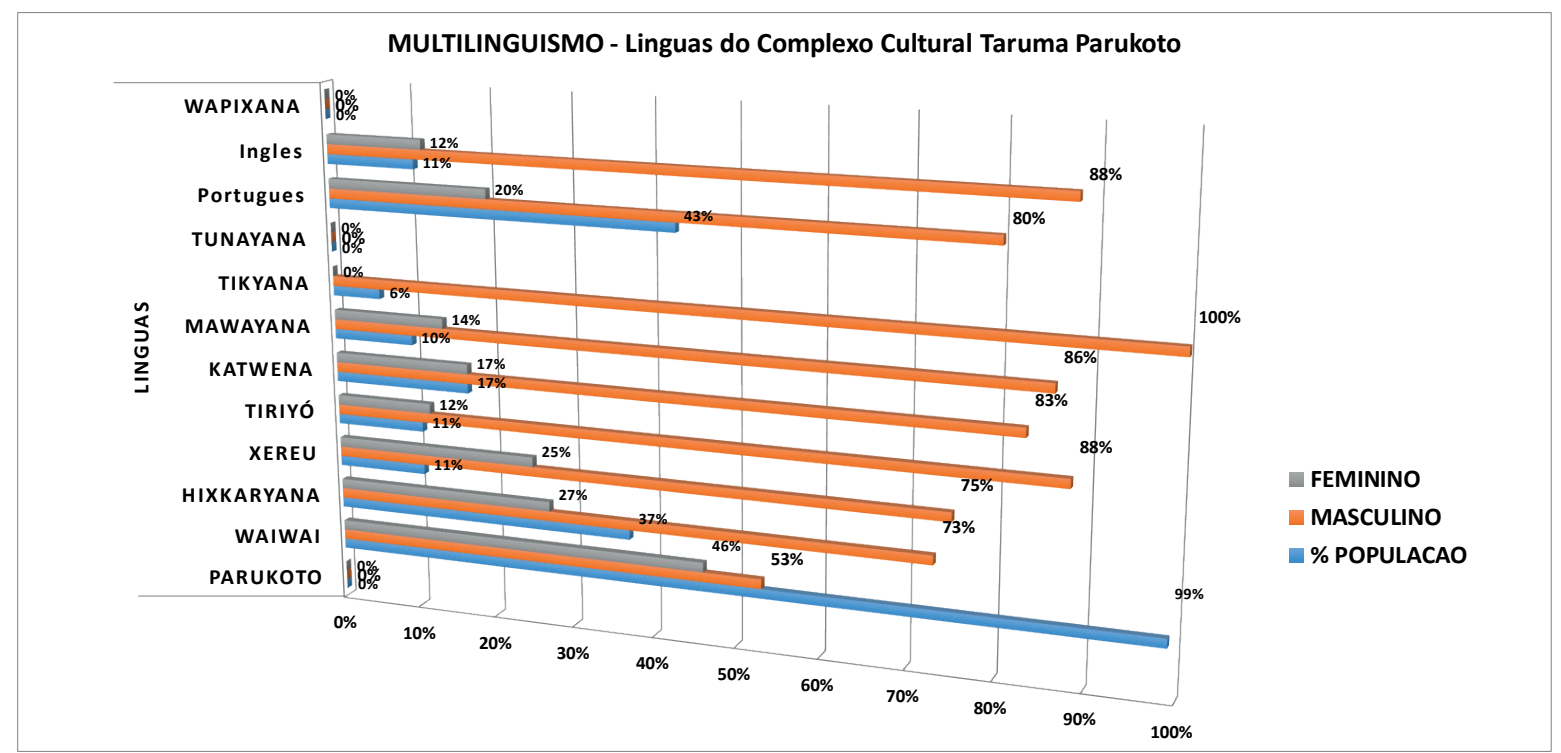

Fonte: RODRIGUES (2020)

Entre os 70 (setenta) colaboradores consultados, durante a coleta de dados, realizada nas aldeias entre os povos indígenas do Complexo Tarumã Parukoto, doze línguas foram reportadas, e entre estas, oito línguas indígenas encontram-se em uso, destacadas durante as pesquisas. É importante atentar para a diferença apresentada pelos dados estatísticos, de forma que $25 \%$ das pessoas consultadas nas aldeias, afirmam serem falantes da língua indígena waiwai, reiterando que o status da língua waiwai passou de língua franca para língua de prestígio e se torna agora, dentro do contexto etnocultural do Complexo, a língua majoritária diante das outras línguas indígenas faladas naquela região e da língua portuguesa, ao passo que as outras línguas aparecem com status de menor prestígio diante da língua waiwai. Isso significa dizer que, a língua waiwai se fortificou com o passar dos anos e se tornou durante o tempo a língua mais importante entre eles, haja vista, como podemos comprovar no gráfico acima que entre os 70 entrevistados $99 \%$ são falantes da língua Waiwai.

Segundo Paulo Wirki Waiwai 5 e outras lideranças das comundades, os fatores de fortalecimento e uso da língua waiwai de forma mais significativa são feitos a partir dos movimentos de dispersão e de fusão que acontece entre os Waiwai e outros povos indígenas. Segundo eles, é uma concepção política recente, que vem sendo discutida e fortalecida entre as lideranças indígenas, por perceberem que só através da homogeneização entre os diferentes povos indígenas e suas culturas ancestrais é que se poderão conseguir visibilidade e voz para lutar contra as políticas de silenciamento/apagamento das culturas indígenas do Brasil. Entendem que se continuarem fragmentados em disferentes etnias e diferentes línguas indígenas, não conseguirão expressão significativa para lutar por seus direitos e suas terras. Para eles é estrategicamente mais interessante investir em uma unificação das etnias e de suas línguas, de forma a assumirem a etnia waiwai, mas não deixando de lado sua etnia e línguas de nascimento, só expõem com mais relevância a língua e a etnia waiwai por as considerá-las mais forte, mais significativas politicamente e as tomam, como representação de um povo unificado.

5. Professor de Ensino Fundamental da rede Municipal de Oriximiná do Estado do Pará.

Revista Brasileira de Línguas Indígenas - RBLI ISSN 2595-685X https://periodicos.unifap.br/index.php/linguasindigenas

Macapá, v. 3, n. 1, p. 135-149, 2020 


\section{Considerações Finais}

Todas as línguas desenvolvidas são plenamente expressivas no sentido semântico. São cheias de significados incorporados ao léxico ou à gramática de uma língua determinando os padrões de pensamento dos falantes como apontam Franchi (2002) e Geraldi (1996), que "sujeito e linguagem perfazem-se mutuamente num contexto sócio-histórico, a partir do processo linguístico-interativo". A linguagem segundo Araújo (2001) "é provavelmente a marca mais notável da cultura e da expressão de um povo. As trocas simbólicas permitem a comunicação, geram relações sociais, possibilitam o pensamento abstrato e os conceitos. É na/e pela linguagem que se pode, não somente expressar ideias e conceitos, mas significar como um comportamento a ser compreendido, isto é, como um comportamento provoca reações e relações".

Entre as relações de expressão das sociedades, surgem vários fatores que devem ser levados em conta os quais estão envolvidos nos sistemas de comunicação. Muitos deles surgem com base em questionamentos e vão se expandindo, surgindo e dando origem a outros, empurrando nossa curiosidade para as realizações das pesquisas em comunidades linguísticas pouco observadas. Muitas delas merecem nossa atenção, especialmente por abrigar todos aqueles conhecimentos ancestrais, que possam surgir em uma simples visita a campo por uma simples explicação de como se faz farinha de mandioca, ou como se coleta a castanha do Pará/Brasil com segurança, como se faz o faafá de castanha, ou como se vence as corredeiras sinuosas entre as curvas do Mapuera.

Como não se deleitar com essa cultura viva e dinâmica entre os povos, por estar em contato com as famílias seus afazeres diários perguntando e anotando tudo, gravando ou filmando para que não se perdesse nenhum minutinho daquele valoroso saber. Coisas relatadas em língua de nascimento em momentos de alimentação, nos banhos no rio, viagens às outras aldeias, lazer com as crianças, ou até mesmo em momento de oração nas igrejas das aldeias, entre outros. Descobertas fabulosas podem surgir entre os saberes e manifestações linguísticas desse povo tão curioso e hospitaleiro das comunidades originais que é o povo Waiwai.

Com base nessas simples reflexões, um tanto saudosas dos momentos de visita a campo, é que podemos relatar como este trabalho de pesquisa foi elaborado e concluído. Iniciamos levantamentos de pesquisa de cunho sociolinguisticos, socioculturais, etnoculturais e sociohistóricos entre as fontes disponíveis sobre os povos indigenas do Complexo Cultural Tarumã Parukoto. Questionamentos foram levantados como: quais as línguas faladas; como elas estão em contato; qual se tornou a língua mais relevante, por que se tornou a mais importante, quais os motivos para usarem uma língua indígena e não a outra, e quais são as mais expressivas, quais estão ameaçadas, morimbundas ou já não existem mais falantes, entre outros.

Os dados apresentados nas pesquisas demonstram que entre as doze línguas apresentadas no Complexo, a que se destaca, que foi informada como língua de nascimento entre os povos indígenas é a língua Waiwai. Comprova-se através dos dados, o status da língua Waiwai como quase um requisito para alguém ser Waiwai, visto que todos os indivíduos que vivem na aldeia e se autodenominam Waiwai também falam a língua Waiwai. Nossos dados indicam ainda que, entre os povos NÃO

6. O faafá-um tipo de beiju de tapioca- Para isso prepara-se uma mistura de Castanha do Pará/Brasil ralada em raladores artesanais desenvolvidos por eles mesmos nas aldeias, acrescentando-se farinha de tapioca úmida em seguida arrumando a massa preparada nas folhas de bananeira que deverão ser assados no mesmo forno que torram a farinha de mandioca. 
Waiwai, a língua dominante também é Waiwai, reportada como língua materna por mais de dois terços dos entrevistados. Portanto, ainda que falar Waiwai seja quase um requisito para ser Waiwai, é perfeitamente normal também falar Waiwai e pertencer a uma outra etnia, distinta dos Waiwai.

Finalmente, resta dizer algo sobre um aparente paradoxo: se os indígenas das comunidades estudadas usam e preservam suas línguas de nascimento (minoritárias diante de Waiwai), usando-as nos domínios de suas atividades mais tradicionais familiares, como então Waiwai continua se fortalecendo como língua dominante naquela região? A resposta está na estratégia consciente adotada naquelas comunidades, a qual envolve restringir os domínios de uso de Waiwai pelos povos de outras etnias, semelhante a uma língua franca, Waiwai tornou-se a língua de conversão dos missionários, utilizada nos momentos e ambientes religiosos e, posteriormente, em outros domínios de interação interétnica, tornando-se um elemento importante no que hoje seus líderes descrevem como um instrumento de unificação e fortalecimento político de povos falantes de línguas distintas.

\section{Referências}

ARACIL, L.V. Papers de sociolinguística. Barcelona: La Magrana, 1982, p. 23-28. 1965.

ARAUJO, Inês Lacerda. Linguagem e Realidade: do Signo ao Discurso. 2001. Tese (Doutorado em Estudos Linguísticos), Universidade Federal do Paraná, Curitiba, 2001. Disponível em < https://www. acervodigital.ufpr.br>

BAKER, Colin. Foundations of bilingual education and bilingualism. 4.ed. Clevendon, Avon, England: Multilingual Matters, 1993.

BAKHTIN. M. Os gêneros do discurso. In: BAKHTIN. M. Estética da criação verbal. Tradução de Maria Ermantina Galvão Gomes Pereira. São Paulo: Martins Fontes, 1992.

BLANK, C.; ZIMMER, M. C. A influência da grafia em tarefa de acesso lexical envolvendo a L2 (francês) e a L3 (inglês) de um multilíngue: uma abordagem via sistemas dinâmicos. Calidoscópio (UNISINOS), v. 9, p. 28-40, 2013.

$\mathrm{BROCH}$, Ingrid Kuchenbecker. Ações de promoção de pluralidade linguística em contextos escolares. 2014. Tese (Doutorado em Letras), Universidade Federal do Rio Grande do Sul, Porto Alegre, 2014. Disponível em <http://hdl.handle.net/10183/102190>. Acesso em: 05 dez. 2020.

CAIXETA DE QUEIROZ, R. Olhares e Perspectivas que fabricam a diversidade do passado e do presente: por uma arqueologia etnográfica das bacias dos rios Trombetas e Nhamundá. Anuário Antropológico, v. 39, n 2, pp. 161-200, 2014.

CALVET, L.J Sociolinguística: uma introdução crítica. Tradução de Marcos Marcionilo. São Paulo: Parábola, 2009.

CENOZ, J. Research on multilingual acquisition. In CENOZ, J.; JESSNER, U. (Eds.). English in Europe: the acquisition of a third language. Clevedon: Multilingual Matters, 2000, p. 39-53.

CUMMINS, J. The role of primary language development in promoting educational success for language minority students. In California State Department of Education (Ed.). Schooling and Language Minority Students: A theoretical frameworks. Los Angeles: California State Department of Education, 1981. 
FERGUSON, C. Diglossia. Word, v. 15, pp. 325-340, 1959.

FISHMAN, J.A. Sociolinguistics. In FISHMAN, J. A. (Ed.). Handbook of language and ethnic identity. New York: Oxford University Press, 1999, p. 152-163.

FRANCHI, C. Linguagem: atividade constitutiva. Revista do Gel, n. especial, 37-74. 2002.

FRIKEL, Protásio. Classificações linguístico-etnológica das tribos indígenas do Pará seoyageecoe zonas adjacentes. Revista de Antropologia, 1958.

FRIKEL, Protásio. Os Kaxuyana: notas etno-históricas. Publicações Avulsas (Museu Paraense Emílio Goeldi), 1970.

FUNAI. Índios no Brasil. Disponível em <http://www.funai.gov.br/index.php/indios-no-brasil/quemsao?start=1>. Acesso em 03 abr. 2020.

GERALDI, J. W. Linguagem e ensino: exercícios de militância e divulgação. Campinas, SP: Mercado de Letras, 1996.

GROSJEAN, F. Studying bilinguals. Oxford: OUP, 2008.

GUPPY, Nicholas. Wai-Wai: through the Forests North of the Amazon. London: John Murray, 1958.

HAWKINS, Neill W. A Fonologia da Língua Uaiuai. Boletim etnografia e tupiguarani. pp. 1-49, 1952.

HAWKINS, Eric. Awareness of language: An Introduction. Cambridge: Cambridge University Press, 1984 .

HOWARD, Catherine Vaughan. A domesticação das mercadorias: estratégias Waiwai. In ALBERT, Bruce; RAMOS, Alcida Rita (Orgs). Pacificando o branco: cosmologias do contato no Norte-Amazônico. São Paulo: Editora UNESP. 2002.

ISA. Povos Indígenas no Brasil, 2006. Disponível em <http://pib.socioambiental.org/pt>.

MEIRA, Sérgio. A família linguística Caribe (Karíb). Revista de Estudos e Pesquisas, FUNAI, Brasília, v.3, n.1/2, p.159-16o, jul./dez. 2006.

PORRO, Antônio. Notas sobre o antigo povoamento indígena do alto Trombetas e Mapuera. Boletim do Museu Paraense Emílio Goeldi (Ciências Humanas), v. 3, n. 3, pp. 387-397, 2008.

RODRIGUES, L. M. S. Educação bilíngue em território indígena waiwai/aldeia Tawanã. 2012. Dissertação (Mestrado em Letras), Universidade Federal do Pará, Belém, 2012. Disponível em <wwww.repositorio. ufpa.br>.

ROMAINE, S. Language in society: an introduction to sociolinguistics. London: Blackwell, 1994.

ROMAINE, Suzanne. Bilingualism. 2. ed. Oxford: Basil Blackwell, 1995.

VIVEIROS DE CASTRO, Eduardo. Imagens da natureza e da sociedade. In VIVEIROS DE CASTRO, Eduardo. A Inconstância da alma selvagem e outros ensaios de antropologia. São Paulo: Cosac Naify, 2002.

ZEA, Evelyn Schuler. Antropologia enviesada: rodeios metafóricos e traduções impróprias Waiwai, In Colóquio Guiana Ameríndia: História e Etnologia, 2006, Belém. Anais... Belém, 2006. 